\title{
Diffuse lamellar keratitis in the femtosecond- assisted LASIK flap tunnel
}

This article was published in the following Dove Press journal:

Clinical Ophthalmology

3 June 2014

Number of times this article has been viewed

\author{
George D Kymionis ${ }^{1,2}$ \\ Konstantinos I Tsoulnaras' \\ Nikolaos G Tsakalis' \\ Michael A Grentzelos' \\ 'Vardinoyiannion Eye Institute of \\ Crete, Faculty of Medicine, University \\ of Crete, Heraklion, Crete, Greece; \\ ${ }^{2}$ Bascom Palmer Eye Institute, Miller \\ School of Medicine, University \\ of Miami, Miami, FL, USA
}

\begin{abstract}
Here we report a case of a 29-year-old myopic female who underwent femtosecond laser-assisted in situ keratomileusis (LASIK) and, on the first postoperative day slit-lamp examination revealed a dense, white, granular reaction with the presence of some blood droplets (stage I diffuse lamellar keratitis [DLK]) in her left eye, specifically localized into the femtosecond LASIK flap tunnel (not extended to the flap interface). The patient received intensive treatment with topical corticosteroids and 5 days later the granular reaction had completely resolved. A new site of DLK, ie, the flap tunnel, in femtosecond-assisted LASIK is presented. DLK into the flap tunnel could be managed with corticosteroids if detected early, without affecting the flap interface.
\end{abstract}

Keywords: diffuse lamellar keratitis, laser-assisted in situ keratomileusis, femtosecond, corneal vascularization, flap, tunnel

\section{Introduction}

An opaque bubble layer is a rare complication of femtosecond laser-assisted in situ keratomileusis (LASIK), which occurs during intracorneal femtosecond laser ablation when gas bubbles are produced and trapped in the corneal interface. ${ }^{1}$ Although intraoperative complications concerning the opaque bubble layer are not yet elucidated, femtosecond laser manufacturers have designed specific modifications for LASIK flap creation in order to minimize the opaque bubble layer effect. ${ }^{1}$ FS200 Wavelight $^{\circledR}$ (Alcon Laboratories Inc., Fort Worth, TX, USA) provides a venting dissection tunnellike "chimney" modification through which the gas bubbles escape from the interface to the hinge side of the limbus. ${ }^{1}$

Diffuse lamellar keratitis (DLK) is an early post-LASIK sterile complication located mainly in the flap periphery and sometimes extending to the central area of the flap in more aggressive stages, and could lead to decreased vision. ${ }^{2}$ Risk factors have already been described, ie, epithelial defects, endotoxins released from sterilizer reservoir biofilms, traumatic flap dislocation, atopy, and other external agents (eg, instrument cleaning solutions, povidone-iodine). ${ }^{3}$ In this case report, we present a patient with DLK located in the femtosecond LASIK flap "chimney" tunnel.

\section{Case report}

A 29-year-old woman was referred to our institution for a refractive consultation. Uncorrected distance visual acuity was counting fingers in both eyes. Corrected distance visual acuity was $20 / 20$ in both eyes, with a manifest refraction of -7.00 to $1.25 \times 10$ in the right eye and -7.00 to $0.50 \times 180$ in the left eye. Keratometric readings (Galilei ${ }^{\text {TM }}$ dual scheimpflug analyzer; Ziemer Ophthalmology, Biel, Switzerland) were 41.58/40.77 diopters and 42.30/40.48 diopters in the right and left eyes, respectively.
Correspondence: George D Kymionis Vardinoyiannion Eye Institute of Crete, University of Crete, Faculty of Medicine, 71003 Heraklion, Crete, Greece $\mathrm{Tel}+3028 \quad 037 \quad 800$

$\mathrm{Fax}+302810394653$

Email kymionis@med.uoc.gr 
Central corneal thickness was $563 \mu \mathrm{m}$ and $568 \mu \mathrm{m}$ for the right and left eyes, respectively. Ophthalmic examination showed clear corneas with mild vascularization in the corneal periphery, especially in the superior part of the cornea; no other anterior or posterior segment abnormality was detected. LASIK using the Wavelight ${ }^{\circledR}$ FS200 femtosecond laser and the Allegretto ${ }^{\circledR}$ Wave Eye-Q $400 \mathrm{~Hz}$ excimer laser (Wavelight GmbH, Erlangen, Germany) was performed; flap tunnels were created with the same settings in both eyes and orientated superiorly extending from the flap hinge to the limbus. The surgical procedure was conducted uneventfully in both eyes as described in our previous report. ${ }^{4}$

At the end of the procedure, a drop of ofloxacin $0.3 \%$ (Exocin $^{\circledR}$; Allergan, Irvine, CA, USA) was instilled. The patient was examined 60 minutes postoperatively on a slit-lamp (Haag Streit 900; Haag Streit AG, Bern, Switzerland) for flap alignment and adherence. Postoperative treatment consisted of nepafenac $0.1 \%$ drops $\left(\right.$ Nevanac $^{\circledR}$; Alcon Laboratories) four times daily, dexamethasone 1\% (Maxidex $^{\circledR}$; Alcon Laboratories) four times daily, ofloxacin $0.3 \%$ drops four times daily, and sodium hyaluronate drops hourly. The patient was advised to wear a plastic shield during sleep.

On the first postoperative day, uncorrected distance visual acuity was 20/25 in both eyes. However, slit-lamp examination revealed a dense, white, granular reaction combined with some blood droplets (stage I DLK) in the flap "chimney" tunnel of the left eye (Figure 1A); the flap was well positioned and the interface was clear. The remainder of the slit-lamp examination was within normal limits for both eyes. An intensive course (every second hour) of Maxidex together with ofloxacin $0.3 \%$ was prescribed for both eyes.
On the second postoperative day, uncorrected distance visual acuity was 20/20 in the right and 20/25 in the left eye; there was an improvement in DLK of the left eye. During the following days, DLK responded rapidly to the treatment and by the fifth day it was completely resolved (Figure 1B); uncorrected distance visual acuity was 20/20 for both eyes. Corticosteroids were tapered over the next 5 weeks without evidence of DLK recurrence.

\section{Discussion}

The first published report of post-LASIK DLK with microkeratome was from Smith and Maloney in 1998. ${ }^{5}$ MacRae et al reported that post-LASIK DLK is associated with leakage of red blood cells and other intravascular contents from blood vessels into the interface in the early postoperative period. ${ }^{6}$

Corneal vascularization occurs when blood vessels grow into the cornea between the epithelium and Bowman's layer. Chronic contact lens wear is the most frequent etiology; corneal infections and allergy, limbal stem cell dysfunction, blepharitis, and uveitis also induce corneal vascularization. ${ }^{7}$ Wallin et al proposed that, in refractive candidates with superior corneal vascularization, it is preferred that the hinge of the mechanical microkeratome flap should be placed superiorly in order to avoid the DLK complication through bleeding in the cut. ${ }^{7}$

Femtosecond laser in the flap creation step of LASIK raised the incidence of DLK due to higher energy delivery to the corneal stroma compared with flap creation with microkeratome. ${ }^{8}$ Moreover, DLK after femtosecond-assisted LASIK was unrelated to hemorrhage or blood vessel leakage, and it has been hypothesized that increased energy and
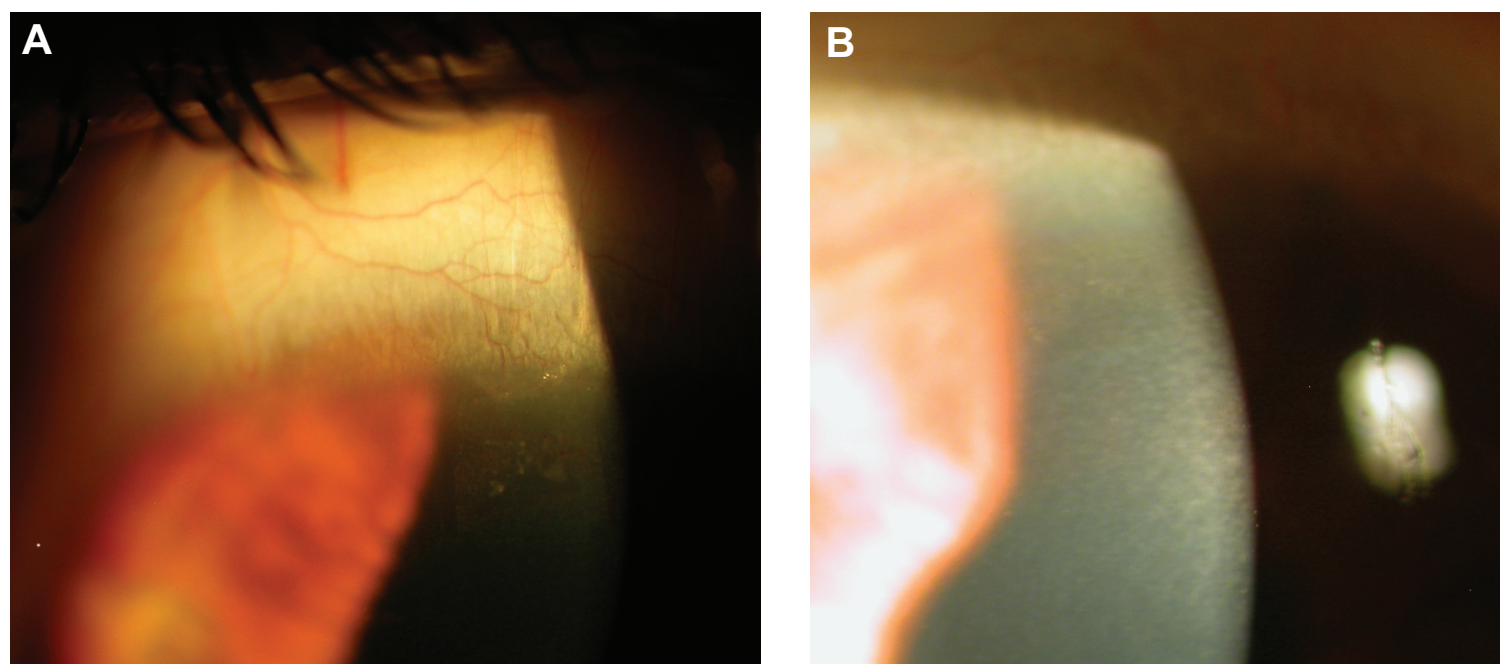

Figure I Slit-lamp photograph on the first postoperative day (A) showing white granular reaction with the presence of blood droplets, resembling diffuse lamellar keratitis into the flap tunnel. On the fifth postoperative day, diffuse lamellar keratitis was completely resolved after corticosteroid treatment (B). 
gas bubble formation in the interface may correlate with this granular reaction. ${ }^{8-10}$

In this report, we present a case of DLK that occurred in the LASIK flap like-chimney tunnel, which is created with the femtosecond laser and facilitates the exit of gas bubbles from the interface to the hinge side of the limbus. The patient had binocular peripheral corneal vascularization due to possible chronic contact lens use and intolerance. Thus, we believe that, during flap tunnel creation, blood vessels from corneal vascularization were damaged in the left eye, leaving blood cells and intravascular contents inside this venting chimney causing postoperative DLK. However, the right eye was unaffected; a possible explanation is that during the cutting process of the femtosecond laser in the right eye, blood vessels were absent or remained intact at the flap tunnel site.

Moreover, epithelial ingrowth, infectious keratitis, and interface foreign bodies were excluded from the differential diagnosis as the reaction occurred immediately after surgery (first postoperative day) into a confined sterile corneal cavity (the LASIK flap tunnel). DLK inflammation was restricted to the tunnel and no reaction was noted in the flap interface; visual acuity remained stable at 20/20. In addition, DLK was easily managed with corticosteroid treatment and 5 days later was completely resolved.

To the best of our knowledge, this is the first report of DLK into the femtosecond LASIK flap tunnel. Damage of the blood vessels during underlying corneal vascularization may trigger this inflammatory reaction. Refractive candidates with chronic contact lens use and evident corneal vascularization should be carefully examined immediately after a LASIK procedure and the first postoperative day for possible DLK in the periphery. Creation of the femtosecondassisted LASIK flap tunnel could be avoided in these patients; the flap tunnel could be placed with a different orientation if corneal vascularization is not extended into the entire corneal periphery (eg, superior corneal vascularization). In patients with more severe corneal vascularization (pannus), additional considerations should be given to treating with other refractive modalities, such as photorefractive keratectomy instead of LASIK.

\section{Acknowledgment}

This research was supported as a part of the special research account at the University of Crete.

\section{Disclosure}

The authors have no financial or proprietary interest in any materials or methods described herein.

\section{References}

1. Kanellopoulos AJ, Asimellis G. Digital analysis of flap parameter accuracy and objective assessment of opaque bubble layer in femtosecond laser-assisted LASIK: a novel technique. Clin Ophthalmol. 2013;7: 343-351.

2. Linebarger EJ, Hardten DR, Lindstrom RL. Diffuse lamellar keratitis: diagnosis and management. J Cataract Refract Surg. 2000;26: 1072-1077.

3. Holland SP, Mathias RG, Morck DW, Chiu J, Slade SG. Diffuse lamellar keratitis related to endotoxins released from sterilizer reservoir biofilms. Ophthalmology. 2000;107:1227-1234.

4. Kymionis GD, Kontadakis GA, Grentzelos MA, et al. Thin-flap laser in situ keratomileusis with femtosecond-laser technology. J Cataract Refract Surg. 2013;39:1366-1371.

5. Smith RJ, Maloney RK. Diffuse lamellar keratitis. A new syndrome in lamellar refractive surgery. Ophthalmology. 1998;105:1721-1726.

6. MacRae S, Macaluso DC, Rich LF. Sterile interface keratitis associated with micropannus hemorrhage after laser in situ keratomileusis. J Cataract Refract Surg. 1999;25:1679-1681.

7. Wallin TR, Weikert MP, Moshirfar M. Effect of flap hinge placement on post-laser in situ keratomileusis wound healing in the presence of superior corneal vascularization. J Cataract Refract Surg. 2003;29: 2448-2451.

8. Farjo AA, Sugar A, Schallhorn SC, et al. Femtosecond lasers for LASIK flap creation: a report by the American Academy of Ophthalmology. Ophthalmology. 2013;120:e5-e20.

9. Gil-Cazorla R, Teus MA, de Benito-Llopis L, Fuentes I. Incidence of diffuse lamellar keratitis after laser in situ keratomileusis associated with the IntraLase $15 \mathrm{kHz}$ femtosecond laser and Moria M2 microkeratome. J Cataract Refract Surg. 2008;34:28-31.

10. Moshirfar M, Gardiner JP, Schliesser JA, et al. Laser in situ keratomileusis flap complications using mechanical microkeratome versus femtosecond laser: retrospective comparison. J Cataract Refract Surg. 2010;36:1925-1933.
Clinical Ophthalmology

\section{Publish your work in this journal}

Clinical Ophthalmology is an international, peer-reviewed journal covering all subspecialties within ophthalmology. Key topics include: Optometry; Visual science; Pharmacology and drug therapy in eye diseases; Basic Sciences; Primary and Secondary eye care; Patient Safety and Quality of Care Improvements. This journal is indexed on

\section{Dovepress}

PubMed Central and CAS, and is the official journal of The Society of Clinical Ophthalmology (SCO). The manuscript management system is completely online and includes a very quick and fair peer-review system, which is all easy to use. Visit http://www.dovepress.com/ testimonials.php to read real quotes from published authors. 